\title{
Cardiac structure and function in relation to cardiovascular risk factors in Chinese
}

\author{
Yi Zhang, Yan Li, Ming Liu, Chang-Sheng Sheng, Qi-Fang Huang and Ji-Guang Wang*
}

\begin{abstract}
Background: Cardiac structure and function are well-studied in Western countries. However, epidemiological data is still scarce in China.

Methods: Our study was conducted in the framework of cardiovascular health examinations for the current and retired employees of a factory and their family members. According to the American Society of Echocardiography recommendations, we performed echocardiography to evaluate cardiac structure and function, including left atrial volume, left ventricular hypertrophy and diastolic dysfunction.

Results: The 843 participants (43.0 years) included 288 (34.2\%) women, and 191 (22.7\%) hypertensive patients, of whom 82 (42.9\%) took antihypertensive drugs. The prevalence of left atrial enlargement, left ventricular hypertrophy and concentric remodeling was $2.4 \%, 5.0 \%$ and $12.7 \%$, respectively. The prevalence of mild and moderate-to-severe left ventricular diastolic dysfunction was $14.2 \%$ and $3.3 \%$, respectively. The prevalence of these cardiac abnormalities significantly $(P \leq 0.002)$ increased with age, except for the moderate-to-severe left ventricular diastolic dysfunction. After adjustment for age, gender, body height and body weight, left atrial enlargement was associated with plasma glucose $(P=0.009)$, and left ventricular hypertrophy and diastolic dysfunction were significantly associated with systolic and diastolic blood pressure $(P \leq 0.03)$, respectively.

Conclusions: The prevalence of cardiac structural and functional abnormalities increased with age in this Chinese population. Current drinking and plasma glucose had an impact on left atrial enlargement, whereas systolic and diastolic blood pressures were major correlates for left ventricular hypertrophy and diastolic dysfunction, respectively.
\end{abstract}

Keywords: Left atrial enlargement, Left ventricular hypertrophy, Left ventricular diastolic dysfunction, Blood pressure

\section{Background}

Cardiac structure and function are well-studied in Western populations, such as the Framingham Heart Study [1,2], the Rotterdam Study [3], and the Atherosclerotic Risk in Communities (ARIC) Study [4]. Cardiac structural and functional abnormalities, even if at asymptomatic stage, may predict cardiovascular events and mortality [1-8]. In the Framingham Heart Study, the echocardiographically diagnosed left ventricular hypertrophy was associated with a $73 \%$ and $112 \%$ higher risk

\footnotetext{
* Correspondence: jiguangw@gmail.com

${ }^{1}$ Centre for Epidemiological Studies and Clinical Trials, The Shanghai Institute of Hypertension, Ruijin Hospital, Shanghai Jiaotong University School of Medicine, Ruijin 2nd Road, Shanghai 200025, China
}

of cardiovascular mortality, and a $49 \%$ and $101 \%$ higher risk of all-cause mortality in men and women, respectively [1].

Several clinical studies reported prevalence and correlates of left ventricular hypertrophy in Chinese hypertensive patients $[9,10]$. However, there is limited epidemiological data on cardiac structural and functional abnormalities in Chinese population. We therefore performed echocardiographic measurements in the framework of cardiovascular health examinations for employees of a factory located in southeast China. In the present cross-sectional analyses, we investigated the prevalence and correlates of cardiac structural and functional abnormalities, including left atrial enlargement, left ventricular hypertrophy and diastolic dysfunction. 


\section{Methods}

\section{Study participants}

The present study was conducted in the year 2006 in the framework of comprehensive cardiovascular health examinations for all employees (including those retired but still lived in the area of the factory at the time of the study) of a factory located in an isolated coast area, 300 kilometers south of Shanghai [11]. The family members of these employees at least 12 years of age living in the nearby region were also invited for participation. The Ethics Committee of Ruijin Hospital, Shanghai Jiaotong University School of Medicine approved the study protocol. All subjects gave written informed consent.

Of the 1052 study subjects (participation rate 80.7\%), 877 participated in the echocardiographic study. We excluded 34 subjects from the present analysis, because they had poor quality of echocardiogram $(n=9)$, moderate or severe valvular regurgitation or stenosis $(n=20)$, congenital heart disease $(n=3)$, atrial fibrillation $(n=1)$ or hypertrophic cardiomyopathy $(n=1)$. Thus, the number of participants included in the present analysis was 843.

\section{Field work}

One experienced physician measured each participant's blood pressure five times consecutively by conventional sphygmomanometry, after at least 5 minutes rest in the sitting position. These five blood pressure readings were averaged for analyses. The same observer also administered a standardized questionnaire to collect information on medical history, smoking habits, alcohol consumption and the use of medications. Current smoking and drinking were defined as at least smoking one cigarette per day or drinking once per week in the past year, respectively. Daily alcohol consumption was calculated according to the consumption of various types of alcoholic beverages during the past month. In the study area, beer was sold in a bottle of $750 \mathrm{~mL}$, whereas yellow aperitif, rice aperitif and hard liquor were traded in a unit of 500 grams. We estimated that one bottle of beer and a unit of aperitif and liquor contained on average 30, 90 and $200 \mathrm{~g}$ of ethanol, respectively. From the type and quantity of the alcoholic beverages used, we computed daily alcohol consumption in grams per day. Drinking subjects were further categorized into tertiles of daily alcohol consumption, with mild, moderate and heavy drinking defined as daily alcohol consumption $<18 \mathrm{~g} / \mathrm{d}, 18$ to $36 \mathrm{~g} / \mathrm{d}$, and $>36 \mathrm{~g} / \mathrm{d}$, respectively. Hypertension was defined as a blood pressure of at least $140 \mathrm{mmHg}$ systolic or $90 \mathrm{mmHg}$ diastolic, or the use of antihypertensive drugs. One trained technician measured body height and body weight. Body mass index was calculated as body weight in $\mathrm{kg}$ divided by the square of body height in meters. Venous blood samples were taken after overnight fasting for measurements of plasma glucose concentration and concentrations of total, highdensity lipoprotein (HDL), and low-density lipoprotein (LDL) cholesterol and triglycerides.

\section{Echocardiographic measurements}

One echocardiographer performed all echocardiographic measurements using the portable Mylab $30 \mathrm{CV}$ machine (ESAOTE SpA, Genoa, Italy) according to the American Society of Echocardiography (ASE) recommendations. Two-dimensional and color Doppler images were first recorded, and then analyzed offline. Moderate or severe valvular regurgitation or stenosis was diagnosed as valvular heart disease using color Doppler imaging [12].

Left atrial volume was calculated using the ellipse model formula: left atrial volume $=\pi \times(\mathrm{SA} 1 \times \mathrm{SA} 2 \times$ LA) 6 , where SA1 is the M-mode left atrial dimension in the parasternal short-axis view and SA2 and LA are measurements of short- and long-axes in the apical four chamber view at ventricular end-systole [13]. Left atrial volume was standardized to body size, as left atrial volume index. Left atrial enlargement was defined as left atrial volume index $\geq 29 \mathrm{~mL} / \mathrm{m}^{2}$ according to ASE recommendations [14].

Measurements for M-mode guided calculation of left ventricular mass (LVM) were taken in the parasternal short-axis view. Left ventricular internal dimension at end-diastole (LVIDd) and septal (SWTd) and posterior wall thickness at end-diastole (PWTd) were measured. LVM was calculated by the ASE recommended formula [15]: LVM $(g)=0.8 \times\left\{1.04 \times\left[(\text { LVIDd }+ \text { PWTd }+ \text { SWTd })^{3}-\right.\right.$ $\left.\left.(\text { LVIDd })^{3}\right]\right\}+0.6$, and standardized to body size by dividing the raw LVM by body surface area, as left ventricular mass index (LVMI). Relative wall thickness (RWT) was calculated by the formula: $(2 \times$ PWTd $) / L V I D d$, and also used as a measure of left ventricular geometry [14]. Left ventricular concentric remodeling and eccentric and concentric hypertrophy were defined as RWT $>0.42$ and $L V M I \leq 115 \mathrm{~g} / \mathrm{m} 2$ (men) or $L V M I \leq 95 \mathrm{~g} / \mathrm{m} 2$ (women), RWT $>0.42$ and LVMI $>115 \mathrm{~g} / \mathrm{m} 2$ (men) or LVMI $>95 \mathrm{~g} / \mathrm{m} 2$ (women), and $\mathrm{RWT}<0.42$ and LVMI $>115 \mathrm{~g} / \mathrm{m} 2$ (men) or LVMI $>95 \mathrm{~g} / \mathrm{m} 2$ (women), respectively [15].

Mitral and pulmonary venous inflow (pulse-wave Doppler) and left atrial volume index were measured for the diagnosis of left ventricular diastolic dysfunction. Normal, indeterminate, and mild, moderate and severe left ventricular diastolic dysfunction were further classified according to the ASE recommendations [16]. On the basis of the ratio of early transmitral diastolic peak flow (E) and atrial peak flow (A, E/A ratio), and the deceleration time of early transmitral diastolic flow (DTE), all subjects were categorized into 3 groups: category 1 with an E/A ratio $<0.75$ and a prolonged DTE $(>220 \mathrm{~ms})$, category 2 with normal range of E/A ratio (0.75 to 1.5 ) 
and DTE $>150 \mathrm{~ms}$, and category 3 with E/A ratio $>1.5$ and DTE $<150 \mathrm{~ms}$. Category 1 was diagnosed as mild left ventricular diastolic dysfunction. Category 2 was further differentiated as normal, indeterminate or moderate left ventricular diastolic dysfunction, if none, only one or at least 2 of the following 4 abnormalities were respectively present: pulmonary venous systolic velocity less than diastolic velocity $(\mathrm{S} / \mathrm{D}<1)$; pulmonary venous atrial reversal duration greater than mitral A duration more than $30 \mathrm{~ms}$ (ARD-AD > $30 \mathrm{~ms}$ ); peak of pulmonary venous atrial reversal wave more than $35 \mathrm{~cm} / \mathrm{s}(\mathrm{AV}>35 \mathrm{~m} / \mathrm{s})$; and left atrial volume index more than $29 \mathrm{ml} / \mathrm{m}^{2}$. Category 3 was further differentiated as indeterminate or severe left ventricular diastolic dysfunction in the absence or presence of at least 1 of the 4 above-mentioned abnormalities. Only in the presence of all echocardiographic measurements mentioned above, left ventricular diastolic function could be evaluated, so that $150 \mathrm{sub}-$ jects were excluded, leaving 693 subjects in the analysis of diastolic dysfunction.

Left ventricular ejection fraction (EF) was measured by quantitative two-dimensional method (biplane Simpson method) [14].

\section{Statistical methods}

Statistical analysis was performed using SAS software, version 9.1 (SAS Institute, Cary, USA). Means and proportions were compared by the student's $t$-test and Fisher's exact test, respectively. In stepwise linear regression, we forced age, gender, body weight and body height, and considered systolic and diastolic blood pressure, current smoking and drinking, the use of antihypertensive drugs, plasma glucose, and the total-to-HDL cholesterol ratio as potential confounders of left atrial volume, LVM and E/A ratio. We performed stepwise logistic regression analyses to investigate correlates of left atrial enlargement, left ventricular hypertrophy and diastolic dysfunction in the consideration of above-mentioned variables. In the stepwise regression analysis, $P<0.10$ were set as criteria for independent variables to enter and stay in the model. We also applied ANOVA to compare the prevalence of cardiac structural and functional abnormalities according to alcohol consumption, plasma glucose, and systolic and diastolic blood pressure.

\section{Results}

The 843 participants included 288 (34.2\%) women, 191 (22.7\%) hypertensive patients (of whom 82 [42.9\%] took antihypertensive drugs), 87 (10.4\%) patients with hyperlipidemia, 17 (2.0\%) patients with diabetes mellitus, and $2(0.3 \%)$ patients with a LVEF less than $50 \%$. Table 1 shows the characteristics of our study subjects. Men and women had similar age $(43.0 \pm 14.0$ years, range 15 to 79 years), plasma glucose $(4.37 \pm 1.19 \mathrm{mmol} / \mathrm{L})$ and total
Table 1 Characteristics of participants

\begin{tabular}{|c|c|c|c|}
\hline & $\begin{array}{c}\text { Men } \\
(n=555)\end{array}$ & $\begin{array}{l}\text { Women } \\
(\mathrm{n}=\mathbf{2 8 8})\end{array}$ & $P$ \\
\hline Age, years & $43.5 \pm 14.7$ & $42.1 \pm 12.5$ & 0.15 \\
\hline Body height, $\mathrm{cm}$ & $168 \pm 6$ & $158 \pm 5$ & $<0.001$ \\
\hline Body weight, kg & $67.4 \pm 9.9$ & $55.8 \pm 8.0$ & $<0.001$ \\
\hline Body mass index, $\mathrm{kg} / \mathrm{m}^{2}$ & $23.9 \pm 3.1$ & $22.5 \pm 3.1$ & $<0.001$ \\
\hline Body surface area, $\mathrm{m}^{2}$ & $1.80 \pm 0.15$ & $1.58 \pm 0.11$ & $<0.001$ \\
\hline Systolic blood pressure, $\mathrm{mmHg}$ & $124.5 \pm 18.3$ & $117.5 \pm 20.6$ & $<0.001$ \\
\hline Diastolic blood pressure, $\mathrm{mmHg}$ & $76.6 \pm 11.4$ & $72.0 \pm 10.6$ & $<0.001$ \\
\hline Current smoking, \% & $255(46.8)$ & $2(0.7)$ & $<0.001$ \\
\hline Current drinking, \% & $209(38.4)$ & $5(1.8)$ & $<0.001$ \\
\hline $\begin{array}{l}\text { Taking antihypertensive } \\
\text { drugs, } \mathrm{n}(\%)\end{array}$ & $61(11.2)$ & $21(7.4)$ & 0.08 \\
\hline Plasma glucose, $\mathrm{mmol} / \mathrm{L}$ & $4.37 \pm 1.49$ & $4.37 \pm 0.75$ & 0.98 \\
\hline Total cholesterol, mmol/L & $4.85 \pm 0.92$ & $4.76 \pm 0.92$ & 0.17 \\
\hline $\begin{array}{l}\text { Low-density lipoprotein } \\
\text { cholesterol, mmol/L }\end{array}$ & $3.12 \pm 0.83$ & $2.95 \pm 0.83$ & 0.005 \\
\hline $\begin{array}{l}\text { High-density lipoprotein } \\
\text { cholesterol, mmol/L }\end{array}$ & $1.30 \pm 0.35$ & $1.50 \pm 0.37$ & $<0.001$ \\
\hline Triglycerides, mmol/L & $2.17 \pm 1.98$ & $1.57 \pm 1.10$ & $<0.001$ \\
\hline Left atrial volume index, $\mathrm{mL} / \mathrm{m}^{2}$ & $19.3 \pm 4.6$ & $18.6 \pm 3.8$ & 0.03 \\
\hline Left ventricular mass index, $\mathrm{g} / \mathrm{m}^{2}$ & $85.9 \pm 16.2$ & $73.3 \pm 14.3$ & $<0.001$ \\
\hline Relative wall thickness & $0.38 \pm 0.05$ & $0.35 \pm 0.05$ & $<0.001$ \\
\hline Left ventricular ejection fraction, $\%$ & $62.5 \pm 4.9$ & $64.0 \pm 5.0$ & $<0.001$ \\
\hline E/A ratio & $1.15 \pm 0.38$ & $1.25 \pm 0.39$ & $<0.001$ \\
\hline Deceleration time, ms & $196 \pm 28$ & $183 \pm 27$ & $<0.001$ \\
\hline Left atrial enlargement, n (\%) & $15(2.9)$ & $3(1.2)$ & 0.14 \\
\hline Left ventricular hypertrophy, n (\%) & $25(4.5)$ & $17(5.9)$ & 0.38 \\
\hline $\begin{array}{l}\text { Left ventricular diastolic } \\
\text { dysfunction, } \mathrm{n}(\%)\end{array}$ & $95(20.4)$ & $26(11.4)$ & 0.003 \\
\hline
\end{tabular}

Data are mean \pm standard deviation or number with percentage in parenthesis. E/A ratio indicates the ratio of early transmitral diastolic peak flow (E) and atrial peak flow (A). Deceleration time indicates the deceleration time of early transmitral diastolic flow (E). For the definition of left atrial enlargement, left ventricular hypertrophy and diastolic dysfunction, see Methods.

cholesterol $(4.82 \pm 0.92 \mathrm{mmol} / \mathrm{L})$. However, men, compared with women, had a greater body mass index $\left(23.9 \pm 3.1\right.$ vs $\left.22.5 \pm 3.1 \mathrm{~kg} / \mathrm{m}^{2}, P<0.001\right)$, higher systolic/diastolic blood pressure $(124.5 \pm 18.3 / 76.7 \pm 11.4$ vs $117.5 \pm 20.6 / 72.0 \pm 10.6 \mathrm{mmHg}, P<0.001)$, more frequently reported smoking and drinking $(46.8 \%$ vs $0.7 \%, 38.4 \%$ vs $1.8 \%, P<0.001$ ), and had lower HDL cholesterol $(1.30 \pm 0.35$ vs $1.50 \pm 0.37 \mathrm{mmol} / \mathrm{L}, P<0.001)$ and higher LDL cholesterol $(3.12 \pm 0.83$ vs $2.95 \pm 0.83 \mathrm{mmol} / \mathrm{L}$, $P=0.005)$ and triglycerides $(2.17 \pm 1.98$ vs $1.57 \pm 1.10 \mathrm{mmol} / \mathrm{L}$, $P<0.001)$. All echocardiographic measurements were significantly higher in men than women $(P \leq 0.03)$, but women, compared to men, had significantly higher LVEF and $\mathrm{E} / \mathrm{A}$ ratio $(P=0.001)$. 
In continuous analyses, in addition to age, male gender, body height and body weight, left atrial volume was significantly associated with systolic blood pressure $(P<0.001)$ and plasma glucose $(P=0.008)$, LVM with systolic blood pressure $(P<0.001)$, and E/A ratio with diastolic blood pressure $(P<0.001)$ and the total-to-HDL cholesterol ratio $(P=0.003$, Table 2$)$.

In 843 participants, the prevalence of left atrial enlargement, and left ventricular concentric remodeling and hypertrophy was $2.4 \%, 12.7 \%$ and $5.0 \%$, respectively. In 693 subjects with sufficient echocardiographic measurements to evaluate left ventricular diastolic function, the prevalence of left ventricular diastolic dysfunction was $17.5 \%$, with mild and moderate-to-severe stages of $14.2 \%$ and $3.3 \%$, respectively. The prevalence of these cardiac structural and functional abnormalities significantly increased with age, except moderate-to-severe left ventricular diastolic dysfunction $(P=0.08)$. Indeed, the prevalence of left ventricular concentric remodeling increased from $8.3 \%$ in subjects younger than 40 years $(\mathrm{n}=421)$ to $20.9 \%$ in subjects of at least 60 years $(\mathrm{n}=134)$. The corresponding values were from $1.9 \%$ to $13.4 \%$ for left ventricular hypertrophy, and from $1.5 \%$ to 46.6\% for left ventricular diastolic dysfunction (Figure 1).

In addition to age, male gender, body height and body weight, left atrial enlargement was significantly associated with plasma glucose (odds ratio $[\mathrm{OR}]=1.29,95 \%$ confidential interval [CI]: 1.06-1.55), left ventricular hypertrophy with systolic blood pressure $(\mathrm{OR}=1.21$, 95\% CI: 1.02-1.44), and left ventricular diastolic dysfunction with diastolic blood pressure $(\mathrm{OR}=1.29,95 \% \mathrm{CI}$ : 1.03-1.62, Table 3). In addition, the prevalence of left atrial enlargement tended to be higher in drinkers than non-drinkers $(\mathrm{OR}=3.16,95 \% \mathrm{CI}$ : $0.88-11.33, P=0.08)$.

In further analyses, we studied left atrial enlargement in men (too small numbers in women) and left ventricular hypertrophy and diastolic dysfunction in men and women, separately, in relation to their correlates identified from above-mentioned analysis as categorical variables. The prevalence of left atrial enlargement in men increased from $1.29 \%$ in non-drinkers $(n=309)$, to $2.25 \%$ in mild drinkers $(\mathrm{n}=89)$, to $5.56 \%$ in moderate drinkers $(\mathrm{n}=54)$, and to $10.2 \%$ in heavy drinkers $(\mathrm{n}=49$, $P=0.003$ for trend), and remained at low level (1.3\%) in subjects with a plasma glucose concentration below $4.70 \mathrm{mmol} / \mathrm{L}$ (quartiles 1 to 3 ) and increased to $7.3 \%$ in subjects with plasma glucose concentration above $4.70 \mathrm{mmol} / \mathrm{L}$ (quartile 4, Figure 2). The prevalence of left ventricular hypertrophy and diastolic dysfunction increased with higher levels of systolic and diastolic blood pressure, respectively, but with slightly steeper slope in women for hypertrophy ( $P$ for interaction $=$ $0.89)$ and in men for diastolic dysfunction ( $P$ for interaction $=0.30$, Figure 3).

\section{Discussion}

To our knowledge, our study is the first that has reported the prevalence and correlates of the echocardiographically diagnosed left atrial enlargement, left ventricular hypertrophy and diastolic dysfunction in an epidemiological setting in a Chinese population. In our study, the prevalence of left atrial enlargement, left ventricular hypertrophy and diastolic dysfunction was $2.4 \%$, $5.0 \%$ and $17.5 \%$ respectively. The prevalence of these cardiac structural and functional abnormalities increased with age, and for left atrial enlargement also with alcohol consumption and plasma glucose, particularly in men, and for left ventricular hypertrophy and diastolic dysfunction, respectively, also with systolic and diastolic blood pressure.

Our finding is comparable with the results of a recent Vietnamese study [17] and the Strong Heart Study in American Indians for left ventricular hypertrophy [18], and with the results of the Olmsted County studies in the Americans [19] and the MONICA study in Germans [20] for left ventricular diastolic dysfunction. In 508

Table 2 Cardiac structure and function in relation to conventional cardiovascular risk factors

\begin{tabular}{|c|c|c|c|c|c|c|c|c|c|}
\hline & \multicolumn{3}{|c|}{ Left atrial volume, $\mathrm{ml}$} & \multicolumn{3}{|c|}{ Left ventricular mass, $\mathrm{g}$} & \multicolumn{3}{|c|}{ E/A ratio } \\
\hline & $\beta \pm S E$ & Partial $\mathrm{R}^{2}$ & $p$ & $\beta \pm S E$ & Partial $\mathbf{R}^{2}$ & $p$ & $\beta \pm S E$ & Partial $\mathrm{R}^{2}$ & $p$ \\
\hline Age, (+10 years) & $0.79 \pm 0.22$ & 0.10 & $<0.001$ & $1.09 \pm 0.82$ & 0.03 & 0.18 & $-0.16 \pm 0.01$ & 0.46 & $<0.001$ \\
\hline Gender, $(1=$ man, $0=$ woman $)$ & $0.24 \pm 0.71$ & 0.07 & 0.73 & $23.15 \pm 2.65$ & 0.28 & $<0.001$ & $-0.03 \pm 0.03$ & 0.01 & 0.31 \\
\hline Body height, $(+10 \mathrm{~cm})$ & $-1.10 \pm 0.51$ & 0.03 & 0.03 & $2.45 \pm 1.94$ & 0.03 & 0.21 & $1.39 \pm 1.95$ & 0.01 & 0.47 \\
\hline Body weight, $\mathrm{kg}$ & $0.49 \pm 0.03$ & 0.22 & $<0.001$ & $1.07 \pm 0.13$ & 0.07 & $<0.001$ & $-0.02 \pm 0.01$ & 0.02 & 0.21 \\
\hline Systolic blood pressure, $(+10 \mathrm{mmHg})$ & $0.59 \pm 0.17$ & 0.01 & $<0.001$ & $2.65 \pm 0.61$ & 0.01 & $<0.001$ & - & - & - \\
\hline Plasma glucose, mmol/L & $0.51 \pm 0.19$ & 0.01 & 0.008 & - & - & - & - & - & - \\
\hline Diastolic blood pressure, $(+10 \mathrm{mmHg})$ & - & - & - & - & - & - & $-0.07 \pm 0.01$ & 0.03 & $<0.001$ \\
\hline Total-to-HDL cholesterol ratio & - & - & - & - & - & - & $-0.03 \pm 0.01$ & 0.01 & 0.003 \\
\hline
\end{tabular}

In stepwise linear regression, we forced age, gender, body weight and body height in the model, and considered systolic and diastolic blood pressure, current smoking and drinking, the use of antihypertensive drugs, plasma glucose, and total-to-HDL cholesterol ratio as potential confounders. $P$ value for variables to enter or stay in the model was set at $<0.10$. $\beta$, estimated parameter; $\mathrm{SE}$, standard error; $\mathrm{HDL}$, high density lipoprotein. 

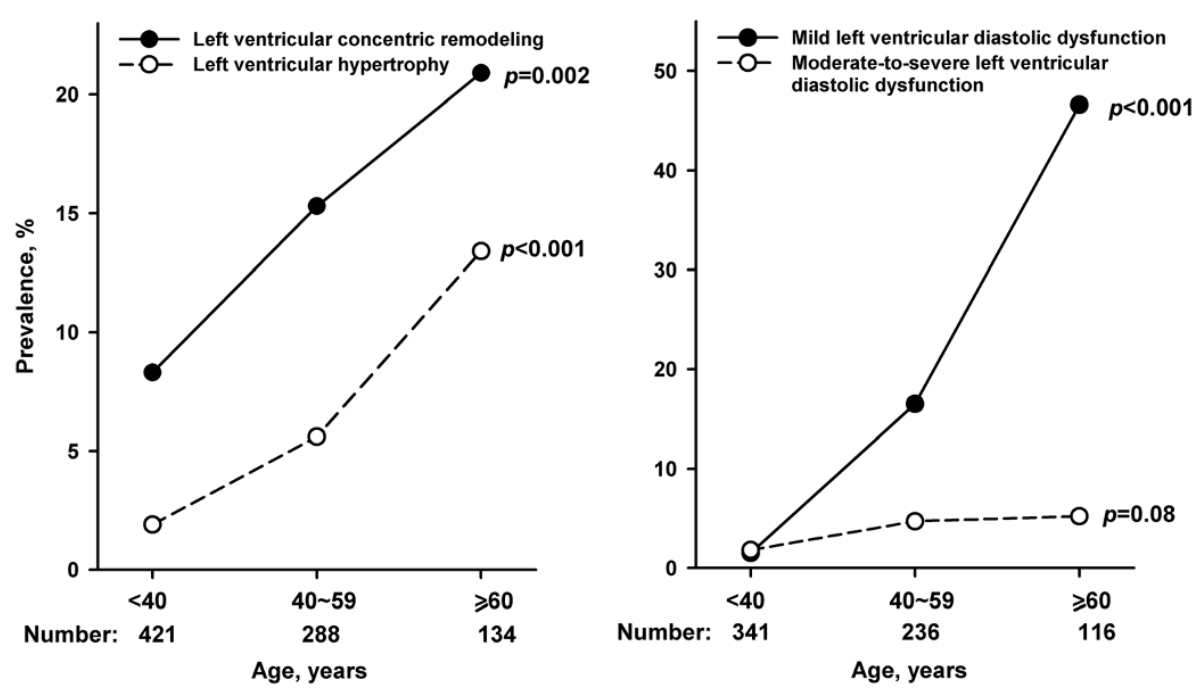

Figure 1 Prevalence of left ventricular structural and functional abnormalities by age. On the left panel, left ventricular concentric remodeling and hypertrophy were presented as filled circles with solid line, and open circles with dashed line, respectively. On the right panel, mild and moderate-to-severe left ventricular diastolic dysfunction was presented as filled circles with solid line, and open circles with dashed line, respectively. The number of subjects for each subgroup is given at bottom, and $P$ for trend for each line at the right side.

Vietnamese, using similar diagnostic technique as ours, the prevalence of left ventricular hypertrophy was $8.5 \%$ [17]. In 2400 participants of the Strong Heart Study, the overall prevalence of left ventricular hypertrophy was 6.8\% [18]. In 2042 American residents of Olmsted County, the prevalence of mild, moderate and severe left ventricular diastolic dysfunction was $20.8 \%, 6.6 \%$ and $0.7 \%$, respectively, and significantly increased with age [19]. In 1274 Germans in the MONICA study, the prevalence of mild and moderate-to-severe left ventricular diastolic dysfunction was $11.1 \%$ and $3.1 \%$, respectively [20].

There is clear and solid evidence that left ventricular hypertrophy was significantly associated with increased systolic blood pressure. We found a significant and linear association between left ventricular diastolic dysfunction and diastolic blood pressure, with a slightly steeper slope in men than in women. This association could be explained by many possibilities. Peripheral resistance is a major determinant of diastolic blood pressure. When vascular remodeling in arterioles is developed, peripheral resistance increases and coronary flow reserve decreases, which in the long run may cause myocardial ischemia, fibrosis, and diastolic dysfunction, before systolic dysfunction develops. Thus, it is possible that arterial remodeling is the common cause of diastolic dysfunction and high diastolic blood pressure. One recent study might lend indirect support for this explanation [21]. In 233 subjects, diastolic dysfunction was significantly associated with increased augmentation

Table 3 Cardiac structural and functional abnormalities in relation to conventional cardiovascular risk factors

\begin{tabular}{|c|c|c|c|c|c|c|c|c|c|}
\hline & \multicolumn{3}{|c|}{ Left atrial enlargement * } & \multicolumn{3}{|c|}{ Left ventricular hypertrophy * } & \multicolumn{3}{|c|}{ Left ventricular diastolic dysfunction * } \\
\hline & Odds ratio & $95 \% \mathrm{Cl}$ & $p$ & Odds ratio & $95 \% \mathrm{Cl}$ & $p$ & Odds ratio & $95 \% \mathrm{Cl}$ & $p$ \\
\hline Age, (+10 years) & 2.67 & $1.45-4.93$ & 0.002 & 1.49 & $1.11-2.01$ & 0.009 & 3.08 & $2.40-3.95$ & $<0.001$ \\
\hline Gender, (1 = man, $0=$ woman $)$ & 0.31 & $0.05-1.94$ & 0.21 & 0.78 & $0.36-2.17$ & 0.78 & 0.87 & $0.44-1.74$ & 0.70 \\
\hline Body height, $(+10 \mathrm{~cm})$ & 1.09 & $0.37-3.20$ & 0.88 & 0.72 & $0.36-1.44$ & 0.35 & 1.04 & $0.64-1.69$ & 0.88 \\
\hline Body weight, $\mathrm{kg}$ & 1.10 & $1.03-1.18$ & 0.003 & 1.02 & $0.98-1.07$ & 0.31 & 1.06 & $1.02-1.09$ & $<0.001$ \\
\hline Current drinking, $(1=$ yes, $0=$ no $)$ & 3.16 & $0.88-11.33$ & 0.08 & - & - & - & - & - & - \\
\hline Plasma glucose, $\mathrm{mmol} / \mathrm{L}$ & 1.29 & $1.06-1.55$ & 0.009 & - & - & - & - & - & - \\
\hline Systolic blood pressure, $(+10 \mathrm{mmHg})$ & - & - & - & 1.21 & $1.02-1.44$ & 0.03 & - & - & - \\
\hline Diastolic blood pressure, $(+10 \mathrm{mmHg})$ & - & - & - & - & - & - & 1.29 & $1.03-1.62$ & 0.02 \\
\hline
\end{tabular}

* Multinomial logistic regression was applied for left atrial enlargement and left ventricular hypertrophy; and multinomial ordinal logistic regression for left ventricular diastolic dysfunction with $0=$ normal, $1=$ mild diastolic dysfunction, and $2=$ moderate or severe diastolic dysfunction. In stepwise logistic regression, we forced age, gender, body weight and body height in the model, and considered systolic and diastolic blood pressure, current smoking and drinking, the use of antihypertensive drugs, plasma glucose, and total-to-HDL cholesterol ratio as potential confounders. $P$ value for variables to enter or stay in the model was set at $<0.10$. Cl, confidential interval. 

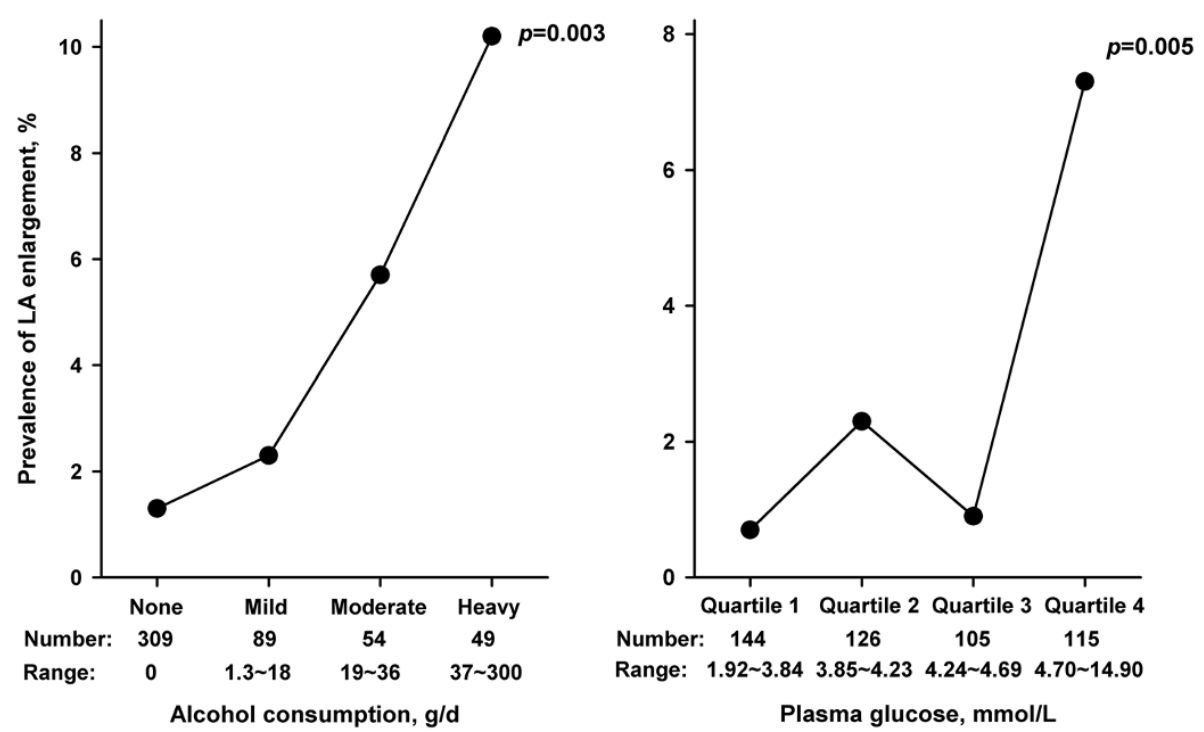

Figure 2 Prevalence of left atrial enlargement in relation to alcohol consumption and plasma glucose in men. Subjects were classified by tertiles of daily alcohol consumption (on the left panel), with non-drinker, and mild, moderate and heavy drinking defined as daily alcohol consumption $=0 \mathrm{~g} / \mathrm{d},<18 \mathrm{~g} / \mathrm{d}, 18$ to $36 \mathrm{~g} / \mathrm{d}$, and $>36 \mathrm{~g} / \mathrm{d}$, respectively, and classified by quartiles of plasma glucose (on the right panel). The number of subjects and the range of values for each subgroup are given at bottom, and $P$ for trend for each line at the right side.

index, which is a hallmark of peripheral remodeling and arterial stiffening. Of course, the cross-sectional design of our study does not allow any causal inference.

Our finding regarding the association between left atrial enlargement and alcohol consumption is in line with the results of two previous studies [22,23]. In 1354 subjects of the HyperGEN study [22], it was reported that left atrial size was positively and significantly associated with alcohol consumption. Similarly, in a relatively smaller study $(n=48)$, left atrial size significantly decreased in chronic alcoholics after a 12-day abstinence [23]. Further studies, especially in a prospective setting, are apparently warranted.

It is unexpected to find a significant association of left atrial volume and enlargement with plasma glucose in the present study. In literature, Milutinović $S$ et al. have reported that hypertensive patients with diabetes, compared to those without, had significantly higher left atrial
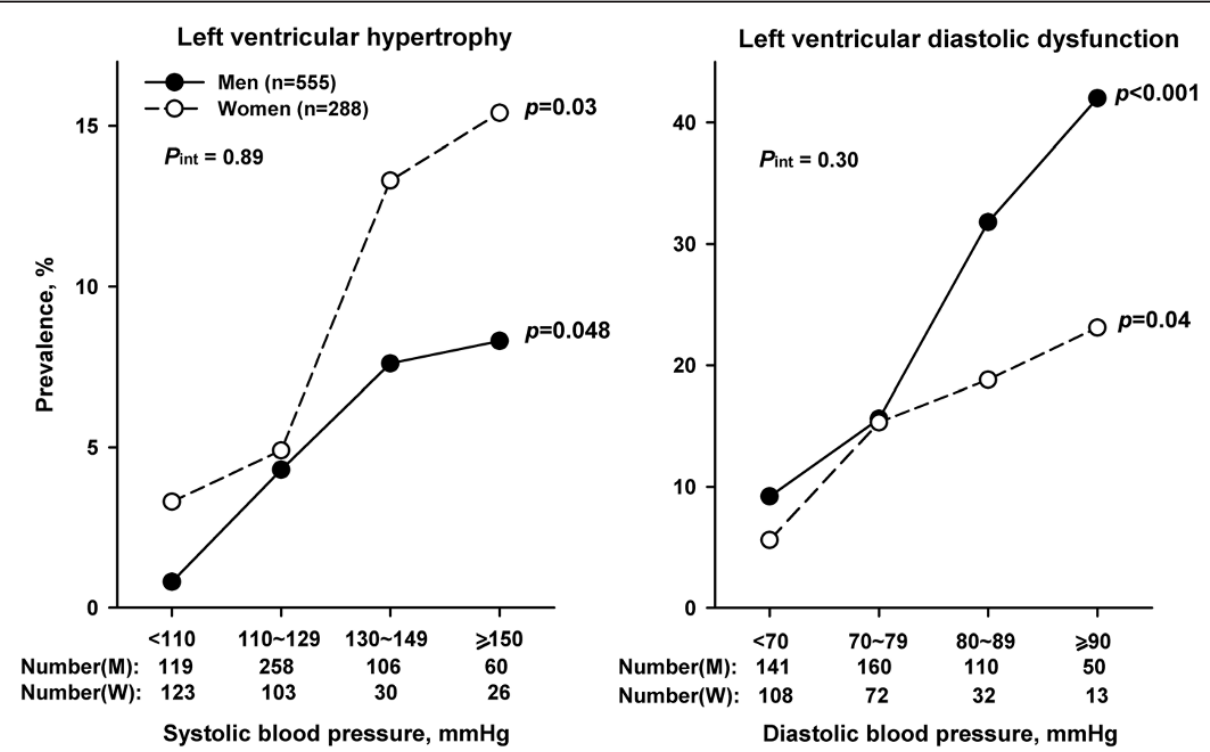

Figure 3 Prevalence of left ventricular hypertrophy and diastolic dysfunction in relation to systolic and diastolic blood pressure. The number of subjects for each subgroup is given at bottom, and $P$ for trend for each line at the right side. 
volume [24]. We found in our study that left atrial enlargement was significantly related to plasma glucose in a nonlinear mode. Patients in the top quartile of plasma glucose had high prevalence of left atrial enlargement (7.2\%), which contributed mostly to the observed significant association. Furthermore, in a subgroup analysis in patients without diabetes $(n=813)$, the associations of left atrial volume index and enlargement with plasma glucose were not statistically significant $(P \geq 0.07)$.

One of the major limitations in the present study is its small sample size, especially in women. In addition, since the present study was conducted in a relatively young and healthy Chinese population, we applied a "low" criterion to define left ventricular hypertrophy, which was also recommended by ASE. If we applied the criterion of LVMI $>125 \mathrm{~g} / \mathrm{m}^{2}$ (men) or $>110 \mathrm{~g} / \mathrm{m}^{2}$ (women) in the present study, our major finding remained unaltered. Specifically, the prevalence of left ventricular hypertrophy would be $1.7 \%(\mathrm{n}=14)$, and its influential factors would include only systolic blood pressure $(\mathrm{OR}=1.04$ [95\%CI: 1.01-1.06], $\mathrm{P}=0.005)$. Secondly, diastolic dysfunction was solely evaluated by Pulse-wave Doppler Imaging, but not Tissue Doppler Imaging in the present study. This technological limitation might, to some extent, influence the accuracy in the classification of diastolic dysfunction. However, this conventional diagnostic technique has been used in most of pervious population studies, and is more applicable in the screening for asymptomatic disease. Lastly, since the present population was recruited in a factory located in southeast China, our finding probably cannot be extrapolated to the entire Chinese population.

\section{Conclusions}

In conclusion, even in a middle-aged and relatively healthy Chinese population, cardiac structural and functional abnormalities, mostly asymptomatic, were prevalent, and had higher prevalence with age advancing and in the presence of several known cardiovascular risk factors, such as heavy drinking of alcohol, hyperglycemia, and high blood pressure. The clinical implications of our finding is that echocardiography probably should be performed for screening subclinical cardiac structural and functional abnormalities, especially in the elderly or in the presence of common cardiovascular risk factors.

\footnotetext{
Abbreviations

HDL: High-density lipoprotein; LDL: Low-density lipoprotein; ASE: American Society of Echocardiography; LVM: Left ventricular mass; LVMI: Left ventricular mass index; RWT: Relative wall thickness; E/A ratio: Ratio of early transmitral diastolic peak flow (E) and atrial peak flow (A); DTE: Deceleration time of early transmitral diastolic flow; LVEF: Left ventricular ejection fraction; OR: Odds ratio; Cl: Confidential interval.
}

\section{Competing interests}

The authors declare that they have no competing interests.

\section{Authors' contributions}

YZ has made substantial contributions to the conception and design of the paper and the analysis and interpretation of data, and been involved in drafting the manuscript. YL, ML, CSS and QFH have participated in patient evaluations, data collection, and the analysis of data. JGW has made substantial contributions to the conception and design of the paper, and been involved in revising the manuscript. All the authors have read and approved the final version of the manuscript.

\section{Acknowledgments}

The authors gratefully acknowledge the voluntary participation of all study subjects and the technical assistance of the physicians and nurses of Haishen Hospital (Xiangshan County, Zhejiang Province). The authors also appreciate the expert assistance of Shou-Yu Mao, Gu-Liang Wang, Jie Wang, and WeiZhong Zhang (The Shanghai Institute of Hypertension, Shanghai, China).

\section{Fundings}

The present study was financially supported by grants from the National Natural Science Foundation of China (30871360, 30871081 and 81170245), Ministry of Science and Technology (2006BAI01A03 and a grant for China-European Union Collaborations 1012), and Ministry of Education (NCET-09-0544), Beijing, China, the Shanghai Commission of Science and Technology (07JC14047 and grants of the "Rising Star" program 06QA14043 and $11 \mathrm{QH} 1402000)$, the Shanghai Commission of Education (07ZZ32 and the "Dawn" project), the Shanghai Bureau of Health (XBR2011004), Shanghai Shenkang Hospital Administration Center (SHDC12007318), Shanghai Jiaotong University School of Medicine (a grant of Distinguished Young Investigators to Yan Li), and the European Union (LSHM-CT-2006-037093 and HEALTH-F4-2007-201550).

Received: 2 February 2012 Accepted: 28 September 2012 Published: 4 October 2012

\section{References}

1. Levy D, Garrison RJ, Savage DD, Kannel WB, Castelli WP: Prognostic implications of echocardiographically determined left ventricular mass in the Framingham Heart Study. N Engl J Med 1990, 322:1561-1566.

2. Krumholz HM, Larson M, Levy D: Prognosis of left ventricular geometric patterns in the Framingham Heart Study. J Am Coll Cardiol 1995, 25:879-884.

3. Kardys I, Deckers JW, Stricker BH, Vletter WB, Hofman A, Witteman JC: Echocardiographic parameters and all-cause mortality: the Rotterdam Study. Int J Cardiol 2009, 133:198-204.

4. Fox ER, Taylor J, Taylor H, Han H, Samdarshi T, Arnett D, Myerson M: Left ventricular geometric patterns in the Jackson cohort of the Atherosclerotic Risk in Communities (ARIC) Study: clinical correlates and influences on systolic and diastolic dysfunction. Am Heart J 2007, 153:238-244.

5. Gardin JM, McClelland R, Kitzman D, Lima JA, Bommer W, Klopfenstein HS, Wong ND, Smith VE, Gottdiener J: M-mode echocardiographic predictors of six- to seven-year incidence of coronary heart disease, stroke, congestive heart failure, and mortality in an elderly cohort (the Cardiovascular Health Study). Am J Cardiol 2001, 87:1051-1057.

6. Rodriguez CJ, Lin F, Sacco RL, Jin Z, Boden-Albala B, Homma S, Di Tullio MR: Prognostic implications of left ventricular mass among Hispanics: the Northern Manhattan Study. Hypertension 2006, 48:87-92.

7. Giannuzzi $P$, Temporelli $P L$, Bosimini E, Silva $P$, Imparato A, Corrà U, Galli M, Giordano A: Independent and incremental prognostic value of Dopplerderived mitral deceleration time of early filling in both symptomatic and asymptomatic patients with left ventricular dysfunction. J Am Coll Cardiol 1996, 28:383-390.

8. Wang M, Yip GW, Wang AY, Zhang Y, Ho PY, Tse MK, Lam PK, Sanderson JE: Peak early diastolic mitral annulus velocity by tissue Doppler imaging adds independent and incremental prognostic value. J Am Coll Cardiol 2003, 41:820-826.

9. Zhan SY, Liu MZ, Yao W, Hu YH, Li LM, Zhu GY, Sun NL, Dai LQ: Prevalence and relevant factors on echocardiograhic left ventricular hypertrophy among community-based hypertensive patients in Shanghai. Chin J Epidemiol 2002, 23:182-185. 
10. Wang HY, Sun NL, Ma Z: Changes of cardiac structure and function in the hospitalized patients with essential hypertension in Beijing. Chin Circ J 2006, 21:352-355.

11. Chen X, Li Y, Sheng CS, Huang QF, Zheng Y, Wang JG: Association of serum uric acid with aortic stiffness and pressure in a Chinese workplace setting. Am J Hypertens 2010, 23:387-392.

12. Bonow RO, Carabello BA, Chatterjee $K$, de Leon AC, Faxon DP, Freed MD, Gaasch WH, Lytle BW, Nishimura RA, O'Gara PT, O'Rourke RA, Otto CM, Shah PM, Shanewise JS, Nishimura RA, Carabello BA, Faxon DP, Freed MD, Lytle BW, O'Gara PT, O'Rourke RA, Shah PM: 2008 focused update incorporated into the ACC/AHA 2006 guidelines for the management of patients with valvular heart disease. J Am Coll Cardiol 2008, 52:1-142.

13. Murray JA, Kennedy JW, Figley MM: Quantitative angiocardiography II. The normal left atrial volume in man. Circulation 1968, 37:800-804.

14. Lang RM, Bierig M, Devereux RB, Flachskampf FA, Foster E, Pellikka PA, Picard MH, Roman MJ, Seward J, Shanewise JS, Solomon SD, Spencer KT, Sutton MSJ, Stewart WJ: Recommendations for chamber quantification: a report from the American Society of Echocardiography's guidelines and standards committee and the chamber quantification writing group, developed in conjunction with the European Association of Echocardiography, a branch of the European Society of Cardiology. J Am Soc Echocardiogr 2005, 18:1440-1463.

15. Devereux RB, Alonso DR, Lutas EM, Gottlieb GJ, Campo E, Sachs I, Reichek N: Echocardiographic assessment of left ventricular hypertrophy: comparison to necropsy findings. Am J Cardiol 1986, 57:450-458.

16. Khouri SJ, Maly GT, Suh DD, Walsh TE: A practical approach to the echocardiographic evaluation of diastolic function. J Am Soc Echocardiogr 2004, 17:290-297.

17. Thai SP, Reid CM, Ngoc QN, Thu HNT, Doan LD, Hai YTT, Lan VN, Gia KP: Association between blood pressure and the prevalence of left ventricular hypertrophy in a Vietnamese population - an echocardiographic epidemiological study [Abstract]. Heart Lung Circ 2008, 17:S46.

18. De Simone G, Kizer JR, Chinali M, Roman MJ, Bella JN, Best LG, Lee ET, Devereux RB: Normalization for body size and population-attributable risk of left ventricular hypertrophy. The Strong heart study. Am J Hypertens 2005, 18:191-196.

19. Redfield MM, Jacobsen SJ, Burnett JC Jr, Mahoney DW, Bailey KR, Rodeheffer RJ: Burden of systolic and diastolic ventricular dysfunction in the community: appreciating the scope of the heart failure epidemic. JAMA 2003, 289:194-202.

20. Fischer M, Baessler A, Hense HW, Hengstenberg C, Muscholl M, Holmer S, Döring A, Broeckel U, Riegger G, Schunkert H: Prevalence of left ventricular diastolic dysfunction in the community. Results from a Doppler echocardiographic-based survey of a population sample. Eur Heart $J$ 2003, 24:320-328

21. Abhayaratna WP, Barnes ME, O'Rourke MF, Gersh BJ, Seward JB, Miyasaka Y, Bailey KR, Tsang TS: Relation of arterial stiffness to left ventricular diastolic function and cardiovascular risk prediction in patients $>$ or $=65$ years of age. Am J Cardiol 2006, 98:1387-1392.

22. Djoussé L, Hunt SC, Eckfeldt JH, Arnett DK, Province MA, Ellison RC: Alcohol consumption and plasma atrial natriuretic peptide (from the HyperGEN study). Am J Cardiol 2006, 98:628-632

23. Breithardt G, Zeitter J, Moritz K, Bluschke V, Lehmann H, Borggrefe M: The effect of alcohol on the heart in chronic alcoholics. Z Kardiol 1988, 77:642-648

24. Milutinović $S$, Karadzić $R$ : The influence of glycemia on the left ventricular diastolic function in patients with arterial hypertension. Med Preg/ 2008, 61:71-74.

doi:10.1186/1471-2261-12-86

Cite this article as: Zhang et al:: Cardiac structure and function in relation to cardiovascular risk factors in Chinese. BMC Cardiovascular Disorders 2012 12:86.

\section{Submit your next manuscript to BioMed Central and take full advantage of:}

- Convenient online submission

- Thorough peer review

- No space constraints or color figure charges

- Immediate publication on acceptance

- Inclusion in PubMed, CAS, Scopus and Google Scholar

- Research which is freely available for redistribution

Submit your manuscript at www.biomedcentral.com/submit 